\title{
REPRESENTATIONAL HANDLING OF POZNAŃ-CRACOW VOICING IN GOVERNMENT PHONOLOGY
}

\author{
GRZEGORZ MICHALSKI \\ Adam Mickiewicz University, Poznań \\ grzegorz@ifa.amu.edu.pl
}

\begin{abstract}
This article discusses the problem of accounting for Poznań-Cracow voicing in Government Phonology. It is concluded that in order for the process to be handled representationally, Polish words beginning with non-obstruents would need to carry the element $\{\mathrm{L}\}$ as part of the melody at the leftmost skeletal slot. It is explained that although such a move would make a representational analysis of Poznan-Cracow Voicing straightforward, the presence of the element $\{\mathrm{L}\}$ on non-obstruents is against the tenets of the phonological model.

The article is organised as follows. Section 1 presents a selection of voice phenomena in Polish. Section 2 introduces the basic concepts of Government Phonology relevant to the analysis. Section 3 summarises Gussmann's (2007) analysis of voice phenomena in Polish. Section 4 discusses the differences between Warsaw Polish and Poznań-Cracow Polish in terms of voice assimilation. Section 5 briefly summarises two earlier analyses of voice phenomena in Polish that account for Poznań-Cracow Voicing, namely Gussmann's (1992) SPE-type analysis of SEGMENTTO-CONSONANT SPREADING, and Rubach's (1996) Lexical Phonology (LP) analysis of CRACOW SPREAD. Section 6 presents theoretical considerations of why these two analyses cannot be mechanically translated into GP theoretical machinery. The section also points to the limitations of Voice AdJustment with respect to Poznan-Cracow Voicing. Section 7 introduces the flawed idea of enriching the left edge of words with the element $\{\mathrm{L}\}$, and provides an attempt at a representational analysis of Poznań-Cracow Voicing using the enriched representation. Section 8 discusses the limitations of the analysis, and proposes an alternative approach to the issue. Section 9 summarises the most important conclusions.
\end{abstract}

KEYWORDS: Polish; Poznań-Cracow Voicing; regressive obstruent voice assimilation; Government Phonology.

\footnotetext{
${ }^{1}$ This paper started as my talk at the 38th Poznań Linguistic Meeting (PLM 2007). However, the discussions I had after my presentation have given me some afterthoughts on the analysis. I would like to thank Tobias Scheer, who pointed to me the weakest points in my original analysis and provided me with some hard-tofind sources. I am also grateful to Edmund Gussmann for our discussions and for helping me access some equally unavailable sources. I should stress that the present article need not be compatible with their views on the subject matter. Finally, I would like to thank the three anonymous $P S i C L$ reviewers of an earlier version of this article. I have tried to include all their remarks in the revised version. As a result, the present version is radically different from my earlier proposal. All the remaining errors are, of course, mine.
} 
1. Some data on voice phenomena in Polish

Spoken Modern Polish has two standard accents, Warsaw Polish and Poznań-Cracow Polish. Due to the geographic spread of these variants, the former is also known as north-eastern Polish, the latter as south-western Polish. The most important difference between the phonologies of these variants - from the point of view of this article - lies in the triggering factors for voice assimilation. This section will concentrate on voice phenomena found in Warsaw Polish. Most of them are also true of Poznań-Cracow Polish. Those that are not will be discussed in Section 4.

With respect to voice, the phonology of Modern Polish exhibits two major types of phenomena: final devoicing, and voice assimilation. Their operation and relevant data are presented in the following subsections.

\subsection{Voice contrast on obstruents}

Voice on obstruents is contrastive. Consider examples in (1) below.

$$
\begin{array}{ll}
\text { pat } \text { [pat] 'stalemate' } & \text { bat [bat] 'whip, n.' } \\
\text { tam } \text { [tam] 'there' } & \text { dam [dam] 'I will give' } \\
\text { sad } \text { [sat] 'orchard' } & \text { zad [zat] '(horse's) croup' }
\end{array}
$$

\subsection{Final devoicing}

Word-finally, obstruents undergo final devoicing, as shown in (2).

$$
\begin{aligned}
& \text { ogrod-u [ogrodu] 'garden' (gen.sg.) ogród [ogrut] } \\
& \text { drzew-o [d } 3 \varepsilon v 0] \text { 'tree' } \sim \text { drzew [d } 3 \varepsilon f] \text { (gen.pl.) } \\
& \text { sad-y } y \text { [sadì] 'orchard' (nom.pl.) } \sim \text { sad [sat] }
\end{aligned}
$$

Due to final devoicing, word-final obstruents do not contrast in voice. Consider examples in (3) below.

$$
\begin{aligned}
& \text { kod-y }[\mathrm{kodi}] \text { 'code' (nom.pl.) } \sim \operatorname{kod}[\mathrm{kot}] \text { (nom.sg.) } \\
& \text { kot-y [koti] 'cat' (nom.pl.) } \sim \operatorname{kot}[\mathrm{kot}](\text { nom.sg.) }
\end{aligned}
$$

\footnotetext{
${ }^{2}$ The stem-final vowel raising $(/ \mathrm{o} / \rightarrow / \mathrm{u} /)$ in this example adds to the claim that underlyingly the final consonant in ogród is a voiced obstruent, as vowel raising appears to be dependent on the existence of a directly following voiced consonant, among other things. For an extensive analysis and rule formulation, see Mid Back Vowel Tensing (rule 197) and Raising (rule 198) in Gussmann (1980) for an SPE-type analysis, or see Gussmann (2007: 261-269) for a GP analysis and discussion.
} 
1.3. Voice assimilation

\subsubsection{Regressive voice assimilation}

Examples in (4) show regressive voice assimilation on obstruents word-internally, with devoicing shown in (4a) and voicing in (4b) (examples in (4b) adapted from Gussmann 2007: 292).

(4a) $\dot{z} a \underline{b}-a[\mathrm{~b}]$ 'frog' $\dot{z} a \underline{b}+\underline{k}-a[\mathrm{p} \mathrm{k}](\mathrm{dim}$.) $z a \underline{b}+e k[\mathrm{~b}]$ 'tooth' (dim.) $\sim z \underline{a} \underline{b}+\underline{k}-a[\mathrm{p} \mathrm{k}]$ (dim.gen.sg.) $k s i a \underline{z}+e k$ [3] 'book' (gen.pl.) $\sim k s i a \underline{\underline{z}}+\underline{k}-i\left[\int \mathrm{c}\right]$ (nom.pl.)

(4b) pros $+i c ́$ [c] 'request, v.' $\sim$ pros $\underline{+}+\underline{b}-a[\bar{z} \mathrm{~b}]$ 'request, n.' licz $+y c$ [t $[\mathrm{t}]$ 'count, v.' $\sim$ licz $+\underline{b}-a[\mathrm{~d} \mathrm{~b}]$ 'number'

Examples in (5) show the same process applying across the word boundary, devoicing being presented in $(5 a)$, and the reverse process in $(5 b)$.

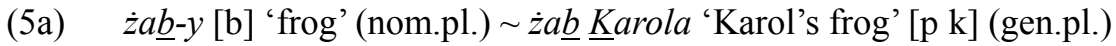
ogrod-y [d] 'garden' (nom.pl.) ogród Piotra [t p p ] 'Piotr's garden'

(5b) but-y $[\mathrm{t}]$ 'shoe' (nom.pl.) but Wiesława $\left[\mathrm{d} \mathrm{v} \mathrm{v}^{\mathrm{j}}\right]$ 'Wiesław's shoe' brat $-a[\mathrm{t}]$ 'brother' (gen.sg.) $\sim$ brat $\underline{\text { Basi }}[\mathrm{d} \mathrm{b}]$ 'Basia's brother'

\subsubsection{Progressive voice assimilation}

Word-internally, sonorants following voiceless obstruents undergo progressive devoicing, as shown in (6).

(6) $\quad \operatorname{prad}[\mathrm{pr}]$ 'current, n.'

$\underline{t t o}[\mathrm{tw}]$ ] 'background'

klatwa $[\mathrm{kl}]$ 'curse, n.'

śnić [cํ.] 'dream, v.'

The effect illustrated in (6) is merely phonetic - voice is not contrastive on sonorants.

\subsubsection{Voice transparency of sonorants}

Sonorants in word-internal obstruent + sonorant clusters are transparent to voice assimilation. Examples in (7) illustrate regressive voice assimilation on these clusters across the word boundary, with devoicing shown in (7a), and voicing in (7b).

(7a) $\quad k a d r-y$ [dr] 'frame, n.' (nom.pl.) kadr szeroki [tro $\left.\int\right]$ 'wide-angle frame' wy $\underline{d r}-a[\mathrm{dr}]$ 'otter' $\sim$ wydr polskich [tr $\mathrm{p}]$ 'Polish otter' (gen.pl.) 
(7b) wiatr-y $[\operatorname{tr}]$ 'wind' (nom.pl.) wiatr z zachodni [dr z] 'westerly wind' baśni-e [cn] 'fairy tale' (nom.pl.) baśn braci Grimm [z] b] 'Grimms' tale'

Also, sonorants in word-final obstruent + sonorant clusters may be transparent to final devoicing of obstruents. Examples in (8) illustrate final devoicing in such clusters.

$$
\begin{aligned}
& k a \underline{d r-y} \text { [dr] 'frame, n., pl' kadr [tr] (nom.sg.) } \\
& \dot{z} u \underline{b r}-y \text { [br] 'wisent, pl.' } \sim \dot{z} u \underline{b r} \text { [pr] (nom.sg.) } \\
& \text { wydm- } a[\mathrm{dm}] \text { 'dune' } \sim \text { wydm [tm] (gen.pl.) }
\end{aligned}
$$

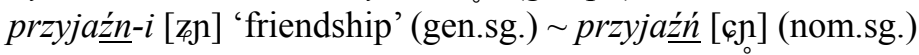

Gussmann (2007: 295) notes that word-final sequences of a voiced obstruent and a sonorant frequently escape final devoicing. Hence, the right-hand word forms in (8) may appear in alternative forms, illustrated in (9) below.

$$
\begin{aligned}
& k a \underline{d r}[\operatorname{tr}] \text { or [dr] 'frame, n.' } \\
& \dot{z} u \underline{b r}[\mathrm{pr}] \text { or [br] 'wisent' } \\
& \text { wydm [tm] or [dm] 'dune' (gen.pl) } \\
& \text { przyjaźn [ç] or [z]]'friendship' }
\end{aligned}
$$

This observation does not invalidate regressive voice assimilation across the sonorant in question - the examples in (7) hold.

Unlike sonorants in word-internal obstruent + sonorant clusters, sonorants found in obstruent + sonorant clusters formed at word junctures are not transparent to voice. They do inhibit regressive voice assimilation. ${ }^{3}$ Consider (10) below (examples in (10b) adapted from Gussmann 2007: 297).

(10a) potok $[\mathrm{k}]$ 'stream' potok $\underline{r w a c y}[\mathrm{k} \mathrm{rv}]$ 'torrent' przestać [tc] 'to stop' przestać lżyć [t 13 ] 'to stop reviling'

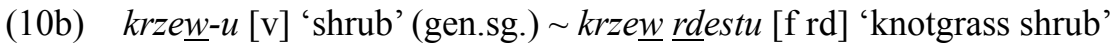
ślad $-y$ [d] 'trace' (nom.pl) śla $\underline{r} \underline{r d z y}$ [t rdz] 'trace of rust'

\section{Government Phonology}

Gussmann's (2007) analysis of Polish is couched in the framework of Government Phonology (henceforth "GP”; Kaye et al. 1985, 1990; Kaye 1990). GP disposes of phonological transformations via ordered rules and absolute neutralisation - as found in SPE (Chomsky and Halle 1968) or Lexical Phonology (henceforth "LP"; Kiparsky 1982; see also Rubach 1984) - to the benefit of phonological representations. What cru-

${ }^{3}$ A PSiCL reviewer points out that this is an observation first made by Rubach and Booij (1990). 
cially distinguishes GP from SPE or LP is that phonological features used in GP are privative, as opposed to binary. GP representations consist of a skeleton, a syllabic tier, and a melodic tier. Consider the example in (11) below.

(11)

wiatr [ $\left.v^{\mathrm{j}} a \operatorname{atr}\right]$ 'wind'

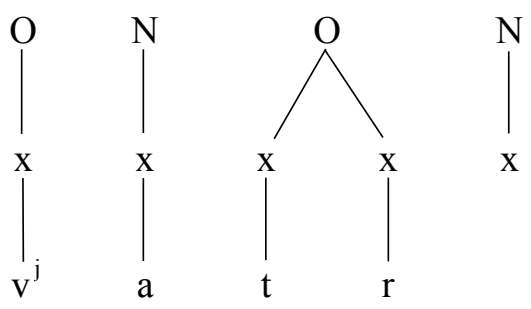

The topmost tier in (11) is the syllabic tier. It consists of alternating onsets ("O") and nuclei ("N"). The middle tier is a standard autosegmental skeleton with $\mathrm{x}$-slots. The remaining tier is the melodic tier. At each $\mathrm{x}$-slot, the syllabic constituent and the melody form a phonological expression - GP's counterpart to structuralist and SPE-like speech segment. Actually, (11) is shorthand for a more complex representation, which is given in (12).

wiatr $\left[\mathrm{v}^{\mathrm{j}} \mathrm{atr}\right]$ ' wind'

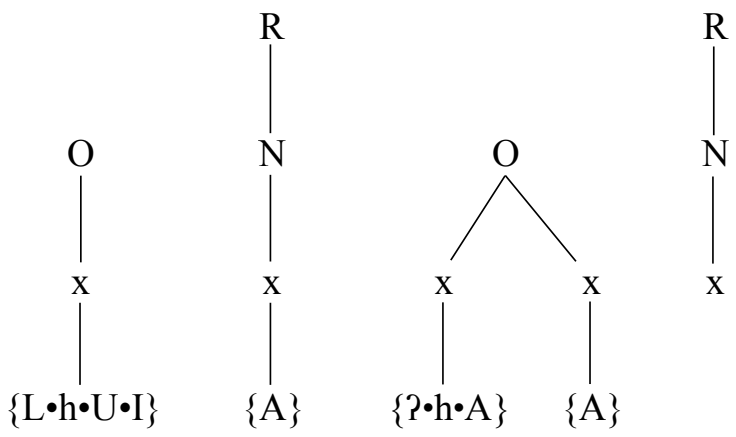

In comparison with (11), (12) has more syllabic constituents, and the melodic tier shows GP elements instead of IPA transcription. On the syllabic tier, a constituent above each nucleus is shown. It is the rhyme (" $\mathrm{R}$ "). Apart from nuclei, rhymes may also contain 
consonantal rhymal adjuncts; in such cases, the nucleus is marked by the intermediate constituent "N", while the adjunct belongs directly under the " $\mathrm{R}$ ". ${ }^{4}$ These cases are of little importance to the present summary. The elements on the melodic tier will be briefly discussed shortly.

A thing of interest is the rightmost slot in (11) and (12). It is a labelled skeletal slot - a nucleus - but its melody is not present. This is a so-called empty nucleus, a sort of a trademark of GP. Its presence in the word-final position is connected with an assumption practised in GP that every representation begins with an onset (an "O" slot) and terminates with a rhyme, which - in case it is phonetically null - takes the form of a final empty nucleus. (For theoretical considerations, and the discussion on empty categories, and on GP tenets in general, the reader is kindly referred to Kaye et al. 1985, 1990; Kaye 1990; Scheer 2004; and Gussmann 2007).

The elements shown on the melodic tier in (12) are the heart of phonological features recognised in GP. They are all privative - monovalent - melodic primes. Their number and role is still under debate in GP, but the ones used in Gussmann's (2007) analysis are given in (13) below (verbatim after Gussmann 2007: 25).

(13) $\{\mathrm{I}\}$ denotes frontness in vowels and palatality in consonants;

\{A\} denotes openness of vowels and coronality in consonants;

$\{\mathrm{U}\}$ denotes rounding of vowels and labiality of consonants;

$\{9\}$ denotes occlusion in consonants;

$\{\mathrm{h}\}$ denotes noise in consonants;

$\{\mathrm{N}\}$ denotes nasality in vowels and consonants;

$\{\mathrm{H}\}$ denotes high tone and voicelessness in consonants;

$\{\mathrm{L}\}$ denotes low tone and voicedness in consonants.

The phonetic interpretation of elements depends on under which syllabic constituent a given element is found. Notice that in (12), there are two instances of the element $\{\mathrm{A}\}$ linked to the skeleton. Their interpretation is different. The left-hand expression, present under an " $\mathrm{N}$ " slot, is interpreted as the open vowel [a]. The other $\{\mathrm{A}\}$ - found under an "O" slot - is interpreted as the coronal sonorant $[\mathrm{r}]{ }^{5}$ Notice that the sonorant is not specified for manner or voice. These are only specified for obstruents. ${ }^{6}$ Manner in obstruents is represented by means of $\{\mathrm{h}\}$, and additionally by means of $\{9\}$ for plosives. Voice is represented either by $\{\mathrm{H}\}$ in languages which do not exhibit final devoicing

\footnotetext{
${ }^{4}$ Following Gussmann's (2007) examples, the present article will take liberty at this point in Section 3 and thenceforth.

${ }^{5}$ Following Gussmann (2007), and for the sake of brevity, examples of GP representations given henceforth will use IPA transcription instead of GP elements on the melodic tier, except for $\{\mathrm{L}\}$ where necessary.

${ }^{6}$ An exception to this rule is nasality, marked by $\{\mathrm{N}\}$ on nasal stops, and nasalised sounds alike.
} 
(e.g. English), or by $\{\mathrm{L}\}$ in languages that do (e.g. Polish) ${ }^{7}$. Thus, it is not viable in a GP analysis of Polish to specify voice on a sonorant or a vowel; these are spontaneously-voiced and never contrast in voice.

Within such a constrained system, one finds Gussmann's (2007) monograph on the phonology of Polish. Chapter 7 thereof is devoted to voice phenomena, on which the next section will report.

\section{Gussmann (2007)}

Having to choose between the element $\{\mathrm{H}\}$ and the element $\{\mathrm{L}\}$ to capture voice distinction on Polish obstruents, Gussmann's (2007: 288-312) analysis settles for the latter to represent voiced obstruents. The present analysis will follow this choice. ${ }^{8}$ The advantage thereof is the simplicity with which Gussmann's analysis treats final devoicing. The process of devoicing obstruents in the word-final position is due to the lack of positional licensing of the element $\{\mathrm{L}\}$ at the right edge of a domain, e.g. a word (Gussmann 2007: 290). Not being licensed, the element in question is suppressed when phonetic interpretation takes place, so that any word-final obstruent emerges voiceless. In order to account for regressive voice assimilation, the analysis makes use of a constraint called VOICE ADJUSTMENT, which is formulated as in (14) below (verbatim after Gussmann 2007: 291).

(14) The tonal specification of the last obstruent controls the laryngeal tier of the sequence.

Notice that although the term "laryngeal tier" does occur in the formulation of (14), this does not translate into the L tier being present in representations in GP. As described by VOICE ADJUSTMENT, obstruent clusters undergo regressive devoicing, which representationally translates into the delinking of the $\{\mathrm{L}\}$ element on all obstruents affected. Conversely, regressive voicing results from linking the same element.

As for the special status of sonorants in voice assimilation - described in section 1.3.3 - Gussmann's VoICE ADJUSTMENT turns out to be sensitive to the syllabic constituency of the sonorant. Consider regressive voice assimilation across word boundaries in (15) (redrawn from Gussmann 2007: 298).

\footnotetext{
${ }^{7}$ Languages may occasionally use both elements if more than two states of the larynx are contrastive on obstruents. Harris (1994: 135) provides a four-way distinction for Gujarati, where a voiced obstruent takes $\{L\}$, a voiceless unaspirated obstruent has no voice specification - i.e. it is unmarked - a voiceless aspirated obstruent has $\{H\}$ in its composition, while a breathy voiced obstruent has both $\{L\}$ and $\{H\}$.

${ }^{8}$ The use of the element $\{L\}$ in analysis of voice contrast in Polish obstruents appears motivated by the discussion in Harris (1994: 133-138). Also, Cyran (2003) uses $\{L\}$ for Polish voiced obstruents.
} 


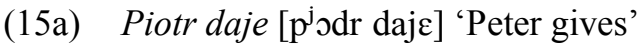

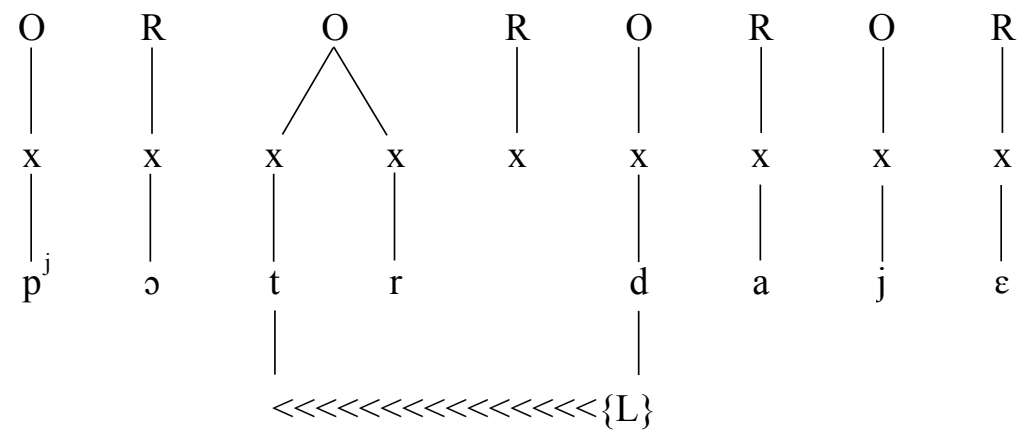

(15b) krzew rdestu [kJef rdestu] 'knotgrass shrub'

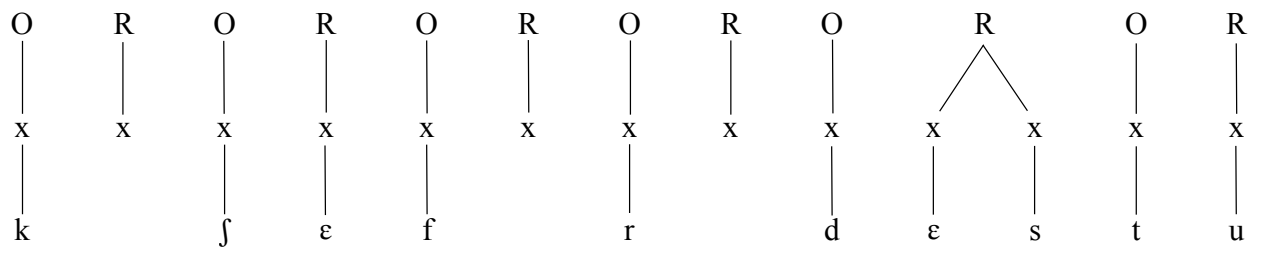

If the sonorant forms a word-final obstruent + sonorant cluster - as in (15a) - VOICE ADJUSTMENT works, because the triggering obstruent from across the word boundary is separated from the target obstruent by only a single empty nucleus. In a reverse situation, when the first word ends in an obstruent, and the second begins with a sonorant followed by an obstruent - as in (15b) - VOICE ADJUSTMENT fails to cross the word boundary, since the sonorant + obstruent sequence of the second word does not form a single onset - such sequences have to be analysed as separate onsets - and the triggering obstruent is separated from its potential target by two empty nuclei, blocking voice agreement. ${ }^{9}$ Gussmann's analysis points to the lack of licensing of two consecutive empty nuclei in GP, and treats (15b) as having two separate domains after the concatenation (Gussmann 2007: 298). Since, however, the adjacency of the two words in (15a) and those in (15b) is equally accidental in phonological terms - the linear order being a matter of syntax - both phrases in (15) must sit in separate domains prior to concatena-

\footnotetext{
${ }^{9}$ If one were to treat this operation as a case of feature spread, then the case in which VOICE ADJUSTMENT fails may be viewed as an effect of locality constraints on feature spread, viz. no hopping across two nuclear positions for onset-driven feature spread.
} 
tion. This indicates that in Gussmann's (2007) analysis, the question whether or not two adjacent words form a single phonological domain is a matter of their edges being able to interact with one another or not. In either case, however, it appears that the words need to be present in their inflected forms before they are made adjacent, at which time VOICE ADJUSTMENT may apply across the juncture. ${ }^{10}$

\section{Regional differences. Poznań-Cracow Voicing}

The voice phenomena described in Section 1 and analysed in Section 3 are uniform across Warsaw Polish and Poznań-Cracow Polish, except that in the latter, sonorants and vowels may trigger regressive obstruent voice assimilation across the word boundary, which in the former is only triggered by obstruents. The vowel- and sonoranttriggered assimilation in Poznań-Cracow Polish is known as Poznań-Cracow Voicing or Cracow Voicing for short. ${ }^{11}$ The examples in (16) below, inspired by Rubach (1996: 72), show the phonetic contrasts between the standards in fast speech.

\begin{tabular}{|c|c|c|c|}
\hline \multirow[t]{2}{*}{ (16a) } & ogród Leona 'Leon's garden' & $\begin{array}{c}\text { Warsaw Polish } \\
{\left[\begin{array}{ll}\mathrm{t} & 1\end{array}\right]}\end{array}$ & $\begin{array}{c}\text { Poznań-Cracow Polish } \\
\text { [d l] }\end{array}$ \\
\hline & ogród Roberta 'Robert's garden' & {$[\mathrm{tr}$ r $]$} & {$[\mathrm{d} \mathrm{r}]$} \\
\hline \multirow{6}{*}{$(16 b)$} & ogród matki 'mother's garden' & {$[\mathrm{t}$ m $]$} & {$[\mathrm{d} \mathrm{m}]$} \\
\hline & ogród ojca 'father's garden' & {$[\mathrm{t} o]$} & {$[\mathrm{d}$ o $]$} \\
\hline & brat Leona 'Leon's brother' & {$\left[\begin{array}{ll}\mathrm{t} & 1\end{array}\right]$} & {$[\mathrm{d} l]$} \\
\hline & brat Roberta 'Robert's brother' & {$[\mathrm{tr} r]$} & {$[\mathrm{d} \mathrm{r}]$} \\
\hline & brat matki 'mother's brother' & {$[\mathrm{t}$ m] } & {$[\mathrm{d} \mathrm{m}]$} \\
\hline & brat ojca 'father's brother' & {$[\mathrm{t} 0]$} & {$[\mathrm{d}$ o] } \\
\hline
\end{tabular}

\footnotetext{
${ }^{10} \mathrm{~A} P S i C L$ reviewer argues that it is not true that the analysis is able to avoid a derivational step. In the reviewer's words " $[. .$.$] the assessment of phonological congruency must be first made in the domain of the$ word before it is made in the domain of the phrase. Thus, we are looking at two derivational stages whose architecture is that of Lexical Phonology: the lexical level and the postlexical level". Indeed, I agree that word forms have to be computed prior to word concatenation. Otherwise, the analysis could not explain final devoicing, for instance. One comment I would like to make, however, would be that, unlike in LP, in GP all processes obey the same set of restrictions - whatever the domain - and that each operation takes place in one step. Hence, the architecture has no separate sets of constraints for what is the lexical and the postlexical level in LP. Also, there is no ordering of constraint application; processes in GP cannot return a representation which would require further processing to "repair" it.

${ }^{11}$ The term "Cracow Voicing" is the one used by Rubach in his (1996) analysis. Gussmann's (1992) analysis uses the term "Cracow-Poznań dialect" when referring to the variant of spoken Modern Polish. My preference is for "Poznań-Cracow Voicing" and "Poznań-Cracow Polish".
} 
Compare the word-boundary situation in the two standards when the word-initial segment in the second word is an obstruent, causing regressive voice assimilation (as described in section 1.3.1); see examples in (17) below.

\begin{tabular}{|c|c|c|c|}
\hline \multirow{3}{*}{$(17 a)$} & & Warsaw Polish & Poznań-Cracow Polish \\
\hline & ogród Dawida 'Dawid's garden' & {$[\mathrm{d} d]$} & {$[\mathrm{d} d]$} \\
\hline & 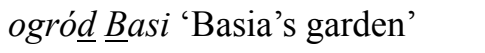 & {$[\mathrm{d} b]$} & {$[\mathrm{d} b]$} \\
\hline \multirow[t]{2}{*}{ (17b) } & brat Dawida 'Dawid's brother' & [d d] & [d d] \\
\hline & brat B Basi 'Basia's brother' & [d b] & {$[\mathrm{d} b]$} \\
\hline
\end{tabular}

As shown in (16) and (17), word-final obstruents lose contrast in voice not only in words in isolation, but also in phrases. While Warsaw Polish ensures the neutralisation across word boundaries by preserving the effect of final devoicing in all contexts except when before voiced obstruents - where regressive voice assimilation has precedence, as shown in (17a) - Poznań-Cracow Polish ensures the neutralisation by assimilating all word-final obstruents to whatever follows, i.e. voicing them when followed by sonorants, vowels and voiced obstruents, and devoicing them when followed by voiceless obstruents or pauses.

Despite the same phonetic setting, voice is not neutralised - and Poznan-Cracow Voicing does not apply - word-internally (including morpheme boundaries), as exemplified in (18).

(18) brat $+o w-a$ [bratova] 'brother's wife'

brat $+n-i$ [bratni] 'brotherly' (masc.)

(Compare examples in (16b).)

It is concluded that Poznań-Cracow Voicing, even though easy to be labelled as "phonetically-motivated" or indeed "phonetic", is phonological in its application; otherwise the prevocalic [ \pm voice] distinction would be lost, contrary to fact. Compare examples in (16) with those in (1), repeated for convenience in (19) below.

$$
\begin{array}{ll}
\text { pat } \text { [pat] 'stalemate' } & \text { bat [bat] 'whip, n.' } \\
\text { tam } \text { [tam] 'there' } & \text { dam [dam] 'I will give' } \\
\text { sad } \text { [sat] 'orchard' } & \text { zad [zat] '(horse's) croup' }
\end{array}
$$

\section{Past analyses}

Within the generative tradition, voice phenomena in Polish have been taken up on a number of occasions (see Gussmann 1992; Rubach 1996; Gussmann 2007, and the references therein). In the following subsections, the article will briefly summarise what can be found on Poznań-Cracow Voicing in Gussmann (1992) and Rubach (1996). 


\subsection{Gussmann (1992)}

In Gussmann's (1992: 53-54) analysis, regressive voice assimilation across word boundaries is analysed as the spreading of voice ("v") from an obstruent onto any consonant via "optional spreading", as in (20), redrawn from Gussmann (1992: 53).

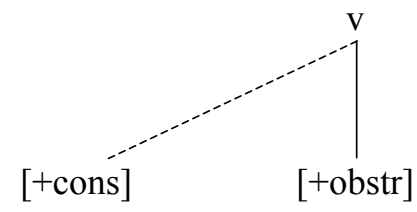

The rule presented in (13) is also called "Obstruent-to-Consonant Spreading" and found operational in Warsaw Polish (Gussmann 1992: 54). For Poznań-Cracow Polish, the optional rule takes the form of any segment ("X") spreading voice onto any consonant, called "Segment-to-Consonant Spreading", and shown in (21), redrawn from Gussmann (1992: 54).

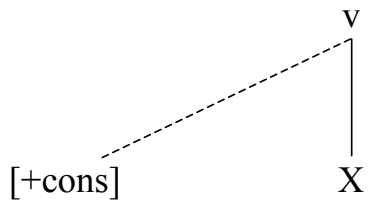

It should be stressed that Gussmann's (1992) analysis allows for segments being unspecified for voice due to syllabic structure violation, and for voice specification on obstruents, sonorants and vowels alike, even though voice can hardly be regarded as contrastive on sonorants and vowels in Polish. Similar reservations can be made towards Rubach's (1996) analysis, a summary of which is presented in the next section.

\subsection{Rubach (1996)}

Rubach's (1996) derivational analysis dispenses with the syllable as playing part in voice assimilation. The triggering factor is claimed to be "linear adjacency of Laryngeal nodes" (Rubach 1996: 69). Within the architecture of LP, all rules relevant to the present discussion are post-lexical - they apply after prosodic words have been computed. For the sake of brevity, only the relevant postlexical part of a derivation including Poznań-Cracow Voicing will be summarised. 
In the phrase brak rdzy ([brak rcki] in Warsaw Polish, but [brag rcki] in PoznańCracow Polish) 'lack of rust' (Rubach 1996: 84), the underlying word-final //k// in brak first passes through FINAL DEVOICING, a rule which delinks the L(aryngeal) node from the R(oot) node on [-sonor] segments - i.e. obstruents - at the end of a phonological word (Rubach 1996: 77). In Poznań-Cracow Polish, the consonant then undergoes CRACOW SPREAD. ${ }^{12}$ CRACOW SPREAD is realised as the spreading of the L node from any segment that has the L node onto the first preceding segment that does not have it, which applies to the word-final //k// after FINAL DEVOICING. CRACOW SPREAD is presented graphically in (22), redrawn from Rubach (1996: 82).

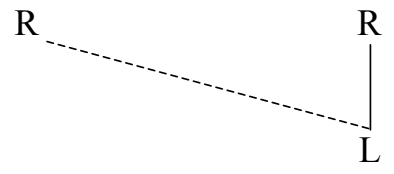

In (22), the sonorant in question may be the $/ / \mathrm{r} / /$ in brak $r d z y$. It should be noted that in Rubach's analysis, the sonorant is specified for [+voice] under its L node; hence, the voicing can be viewed in terms of autosegmental spread of the L node between adjacent segments, but this is only due to [+voice] being representationally present on a segment on which it never contrasts with [-voice]. ${ }^{13}$

\subsection{Summary}

Both Gussmann's (1992) and Rubach's (1996) analyses use voice as a binary ([ \pm voice]) feature that can be specified not only on obstruents, but also on non-obstruents. As such, they contrast with what can be normally done to analyse voice phenomena in GP. This issue is addressed in the next section.

\section{The inapplicability of SPE-type and LP analyses for GP}

Gussmann's (2007) analysis does not account for Poznań-Cracow Voicing. The discussion of this phenomenon in the book is reduced to a single footnote, without a single hint as to how to account for the phenomenon representationally (Gussmann 2007:

\footnotetext{
${ }^{12}$ The remaining rules in Rubach's (1996) analysis are not crucial for Poznań-Cracow Voicing as such. Due to space restrictions, the reader is referred to the original article for discussion of, among others, obstruenttriggered regressive voice assimilation and transparency effects on sonorant consonants, both in Warsaw Polish and Poznań-Cracow Polish.

${ }^{13}$ Word-initial sonorants are never [-voice] in Polish.
} 
301). ${ }^{14}$ It seems Gussmann's analysis does not cover Poznań-Cracow Voicing because the theoretical machinery of GP - largely dependent on underspecification - does not allow for treating this phenomenon as a phonological process consisting of the spread of voice from a sonorant or a vowel to an obstruent. ${ }^{15}$ Recall two examples of VOICE ADJUSTMENT at work given in (15), repeated for convenience in (23) below.

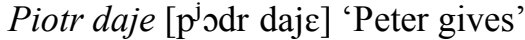
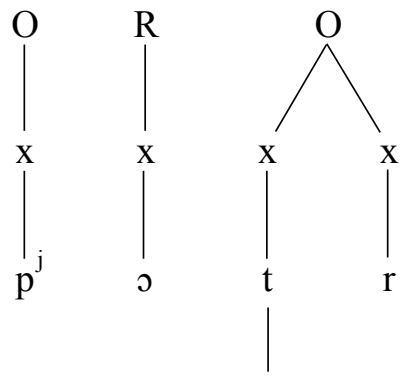<smiles>[R]COC</smiles><smiles>[R][K]</smiles><smiles>[R][Y](C)I</smiles><smiles>[SiH2]=[As]=C=C=C=[As]</smiles>
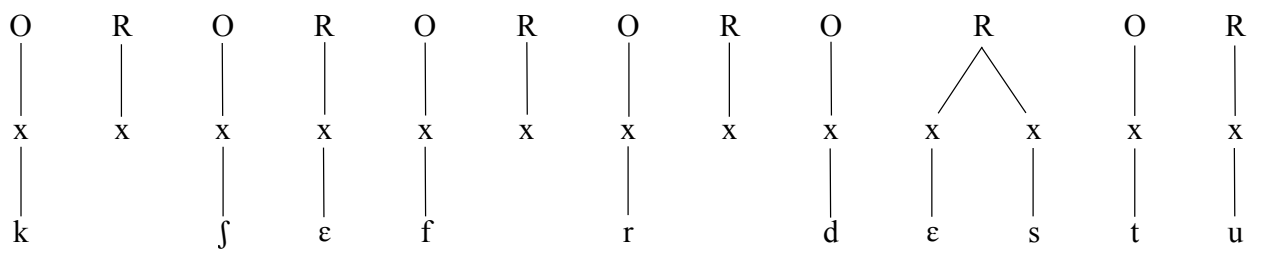

\footnotetext{
${ }^{14}$ Part of the footnote reads: "Various interpretations of this phenomenon have been suggested in the derivational-generative literature but none of them appears very satisfactory and they all smack of gimmicky manipulations encouraged by the theoretical machinery of default filling, voice spreading from sonorants and the like (Bethin 1992; Gussmann 1992; Rubach 1996)" (Gussmann 2007: 301). I presume the hypothetical analysis given in Section 7 herein fits this description. Its major goal, however, is to show the problem with analysing Poznań-Cracow Voicing in GP, rather than to claim that this is the best way to do it. An alternative account is currently under development (Michalski, in prep.).

${ }^{15}$ A reviewer points out that this problem is not GP-specific. Namely, any theory in which sonorants and vowels are not specified for voice and in which voice assimilation is analysed via feature spread should find Poznań-Cracow Voicing problematic. Thus, the issue discussed in this article is not the descriptive deficiency of GP, but rather of any model in which voice is not specified for those natural classes on which it is not contrastive.
} 
The successful application of VOICE ADJUSTMENT in (23a) is due to the voiced obstruent $/ / \mathrm{d} / /$ spreading its element $\{\mathrm{L}\}$ across an empty nucleus, and across the sonorant $/ / \mathrm{r} / /$ - which sits in a branching onset - to the voiceless //t//, which becomes voiced, i.e. [d]. The lack of voice assimilation in (23b) is due to the inability of the element $\{L\}$ in the voiced //d// to spread to the underlyingly voiced //v// across two empty nuclei. The two obstruents remain in separate domains, the //v// being domain-final, and consequently devoicing to [f]. Crucially, the sonorant $/ / \mathrm{r} / /$, not being part of the same onset as $/ / \mathrm{v} / /$, is opaque to voice assimilation. Neither does it influence the $/ / \mathrm{v} / /$ itself. Not being an obstruent, it has no element $\{L\}$ in its melody. Unlike in Gussmann's (1992) and Rubach's (1996) analyses, the sonorant cannot be specified for voicedness in Gussmann's (2007) work, and it is not.

The example in (23b) is true for Warsaw Polish. However, in Poznań-Cracow Polish, the situation would be as in (24) below.

\section{krzew rdestu [kJev rdestu] 'knotgrass shrub’ (Poznań-Cracow Voicing)}

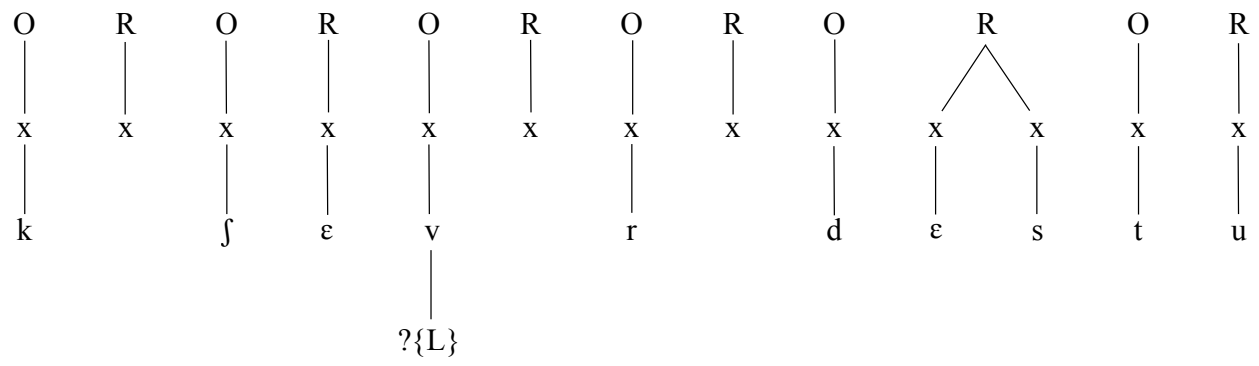

In (24), the word-final //v// is voiced, as if it carried the element $\{\mathrm{L}\}$, against VOICEADJUSTMENT. In Gussmann's (2007) analysis, this behaviour cannot be accounted for. Firstly, the $\{\mathrm{L}\}$ on the word-final $[\mathrm{v}]$ could not have spread from the $/ / \mathrm{d} / /$ across the word boundary. These consonants are separated by two empty nuclei. Secondly, even if the words in (24) are concatenated, this number of empty nuclei disqualifies (24) as a single domain. (Recall that the argument about two words failing to form a singular domain is used by Gussmann (2007: 298) to explain why the word-final //v// is devoiced in (23b).) Thirdly, not being in the same domain as the $/ / \mathrm{r} / /$, the $/ / \mathrm{v} / /$ is domainfinal, where its element $\{L\}$ is not licensed, and the consonant should be voiceless, contrary to fact. ${ }^{16}$ Consider one more example, in (25) below.

\footnotetext{
${ }^{16}$ Notice, however, that the consonant in question is indeed devoiced in Warsaw Polish, to which Gussmann's (2007) analysis applies.
} 
<smiles>[Y][Y]([3H])OC</smiles><smiles>[R][X][SiH](C)O</smiles><smiles>[R][X]O</smiles><smiles>[X]C(O)I</smiles><smiles>C[Y](S)OO</smiles>

As with (24), the example in (25) shows a voiced word-final obstruent - viz. [d]. Similarly to (24), there is no phonological expression with the element $\{L\}$ in $(25)$ that could influence the voicedness of this consonant. In fact, none of the expressions in ojca [ojtsa] 'father' (gen.sg.) is specified for voice in GP. The vowels and the glide [j] are nonobstruents, while the affricate is underlyingly voiceless. (Recall that voice is privative in GP; the lack of $\{L\}$ is not counterbalanced by the presence of $\{H\}$, for that matter.)

It is concluded that Poznań-Cracow Voicing cannot be captured by means of Gussmann's (2007) VOICE ADJUSTMENT. It should be noted, however, that the problem in accounting for Poznań-Cracow Voicing does not make GP inferior to other theories. Firstly, the two previous analyses summarised herein - viz. Gussmann's (1992) and Rubach's (1996) papers - can only capture the phenomenon in question because their representational machinery allows for sonorants and vowels to bear the feature [+voice]. Secondly, while descriptively adequate, those analyses can tell how, but cannot tell why spontaneously-voiced sounds should be active in voice assimilation when they are the very first segment of a (phonological) word, but should have no influence on voice elsewhere. ${ }^{17}$ Indeed, the data in Sections 1.3.2 and 1.3.3 clearly show that, word-internally, sonorant consonants not only have no bearing on the voice of preceding obstruents, but they are systematically devoiced when following voiceless or de-

\footnotetext{
${ }^{17}$ It should be noted that in Gussmann's (1992) and Rubach's (1996) analyses, sonorants in word-initial but not in word-final obstruent + sonorant clusters are specified for [+voice] due to a late adjunction to the syllable node. This may potentially explain the failure of sonorants in word-final obstruent + sonorant clusters to inhibit regressive voice phenomena. It cannot, however, explain why sonorants should only influence the voice of preceding obstruents across the word boundary. Crucially, both analyses postulate that, before word concatenation takes place, word-final obstruent + sonorant clusters - due to their violating of sonority sequencing or other constraints - are specified for [-voice]. It is not the case, then, that Poznan-Cracow Voicing targets segments with no voice specification. Finally, it is not clear at all - even though the data confirm this - why vowels should only bear on the voice of obstruents across the word boundary. In both analyses, all (pronounced) vowels are unanimously syllabified and specified for [+voice], and the obstruents they target across the word boundary are specified for [-voice]. Recall that, word-internally, [ \pm voice] before vowels is preserved; see examples in (1).
} 
voiced obstruents. So far, this observation has not found a satisfactory explanation, as opposed to description. ${ }^{18}$

7. Extraneous element $\{L\}$ as an easy but implausible solution

This section explores the theoretical concept of enriching the leftmost "O" slot of words starting with non-obstruents with the element $\{\mathrm{L}\}$. It should be stressed that this is only a hypothetical solution. Due to its incompatibility with the tenet of GP that nonobstruents are never specified for voice, the proposal discussed in this section is only to show that this representational way of accounting for Poznań-Cracow Voicing is not workable.

Since Poznań-Cracow Voicing is only found at word boundaries, the additional element $\{L\}$ would only affect the left edge of words. In order for the phenomenon in question to be possibly captured by VOICE ADJUSTMENT, the triggering factor must representationally act as a word-initial obstruent; hence, it can only appear under the leftmost "O" slot in the skeleton. Two examples of such a configuration are shown in (26).

(26a) ojca 'father' (sg.gen.) (with an additional $\{\mathrm{L}\}$ )

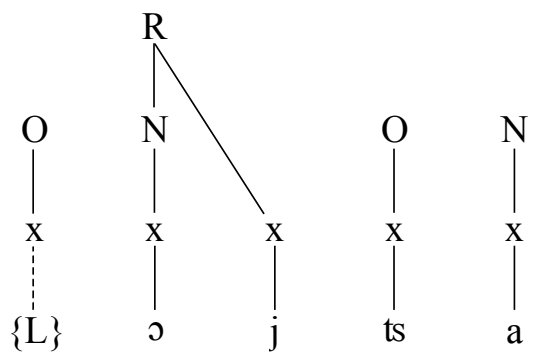

(26b) Leona 'Leon' (sg.gen.) (with an additional $\{\mathrm{L}\}$ )

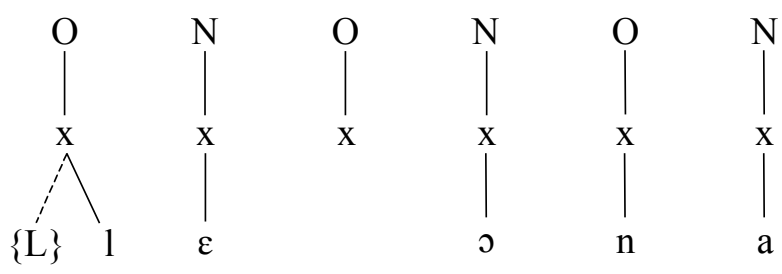

\footnotetext{
${ }^{18}$ In fact, the present article will regrettably not find it, either.
} 
The element $\{\mathrm{L}\}$ is shown attached to the skeleton with a dashed line only for the purpose of exposition. Its presence is essentially a representational marker of the voice feature that the left edge of the words in (26) has phonetically, but which is not lexically specified in GP. It should be noted that the presence of $\{L\}$ under a consonantal slot should be interpretable as nothing but voicedness. If put under an otherwise empty slot - as in (26a) - the presence of $\{L\}$ has no detrimental effects on the interpretation; it carries no information that would cause it to be interpreted as any particular consonant. It only specifies voicedness, which is not contrastive with the vowel that follows. The same applies to the consonantal slot occupied by the sonorant in (26b); the $\{\mathrm{L}\}$ only specifies voicedness on what already is interpretable as a voiced speech sound.

In the examples that follow, only a sonorant-initial case will be used as an exponent of all phonological chunks beginning with a vowel or a sonorant, which in articulatory terms both belong to a natural class of spontaneously-voiced speech sounds.

To show that the presence of the left-edge $\{L\}$ for the purposes of Poznań-Cracow Voicing would only be worth considering for words - not suffixes, for instance - the examples to follow will concentrate on the phrase given in (27), on the string of two suffixes given in (28), and on the word form given in (29) below.

$$
\begin{aligned}
& \text { (27) brat Leona //brat//+//leona// [bradleona] 'Leon's brother' } \\
& \text { (28) }-n-i / / \mathrm{n} / /+/ / \mathrm{i} / /[\text { [ni] adjectival suffix + (nom.sg.masc.) } \\
& \text { (29) } \quad \text { brat }+n-i / / \text { brat//+//n//+//i// [bratni] 'brotherly' (masc.) }
\end{aligned}
$$

The pronunciation of (29) is the same in Poznań-Cracow Polish and Warsaw Polish, while the pronunciation given in (27) is not attested in Warsaw Polish, where it is [bratleona] (see section 4). Consider representations in (30), (31), and (32) below.

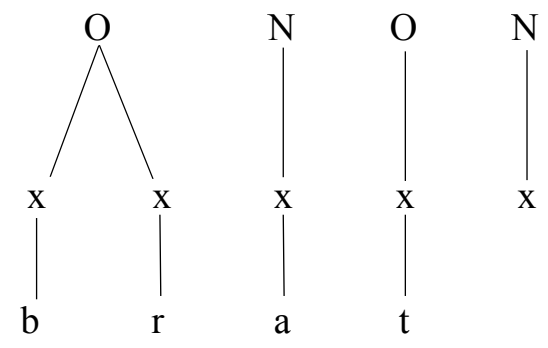


(31) brat Leona //brat//+//leona// [bradleona] 'Leon's brother' (Poznań-Cracow Voicing)

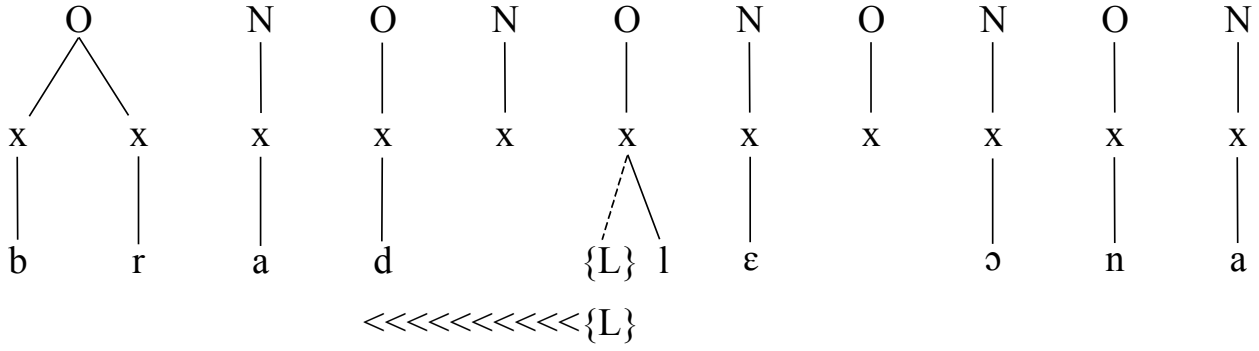

brat $+n-i / /$ brat $/ /+/ / \mathrm{n} / /+/ / \mathbf{i} / /[$ bratni] 'brotherly' (masc.)

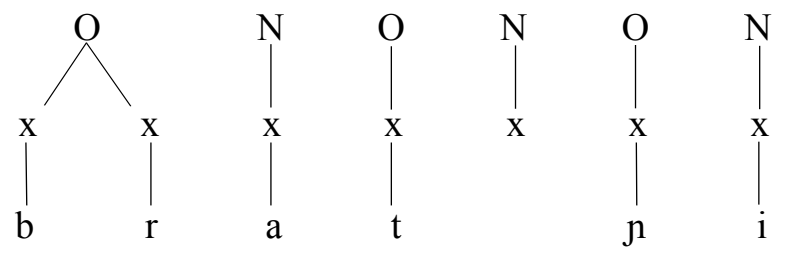

Potentially, if the leftmost onset of a word beginning with a non-obstruent is marked with the element $\{L\}$, Poznań-Cracow Voicing - shown in (31) - would be captured by VOICE ADJUSTMENT, similarly to (23a). The spread would not take place between the base and the suffix in (32), since the suffix has no extraneous $\{L\}$ in its melody.

If there were no differentiation between the left edge of words and the left edge of any representation - including suffixes - the word in (32) would take the form shown in (33) below.

brat $+n-i / /$ brat $/ /+/ / \mathrm{n} / /+/ / \mathrm{i} / /$ *[bradni] 'brotherly' (masc.)<smiles>[Y]CO[Tl]</smiles>

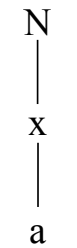<smiles>O[Al][V]O</smiles><smiles>[Y]N</smiles><smiles>N[Y]([In])[Al](O)[AlH]</smiles>

$<<<<<<<<<\{\mathrm{L}\}$ 
The representation in (33) is counterfactual. Word-internally, sonorants (and vowels) do not trigger voicing of underlyingly voiceless obstruents.

\section{Limitations of the analysis}

From what has been shown in Section 7, the adoption of an extraneous element $\{L\}$ on the left-edge "O" slot of a word may appear an autosegmentally-plausible way of analysing Poznań-Cracow Voicing. More importantly, the representational device of adding what - in GP terms - is unambiguously interpretable as the type of voicing typical of obstruents does not introduce any opacity to other voice-related phenomena in Polish. Its use in the present analysis has been restricted to the left edge of words that do not begin with an obstruent. Still, the assumption that the extra $\{\mathrm{L}\}$ should only appear on words, but not on morphemes as such, would have some potential consequences - if only this were a serious analytical proposal. Firstly, this would require a constraint that would (1) enforce (or link) an extraneous $\{\mathrm{L}\}$ on any initial "O" slot in words in which that slot is not occupied by an obstruent; (2) prohibit (or delink) such an $\{\mathrm{L}\}$ on any morpheme-initial "O" slot which is not the initial "O" slot of a word at the same time; and (3) hold only for Poznan-Cracow Polish, never for Warsaw Polish. Secondly, constraints - the way they are usually found in GP - pertain to what may be called "phonology proper". This is a component of grammar that does not by itself distinguish between morphemes and words. ${ }^{19}$ As long as something has a phonological representation, it is computable in phonology, no matter what its identity is. Thirdly, the way it has been presented, the concept of adding the element $\{\mathrm{L}\}$ to "O" slots not occupied by obstruents may be leading to a reasonable but incorrect conclusion that speakers of Warsaw Polish and speakers of Poznań-Cracow Polish should have systematically different underlying representations. Finally, it would appear that these representations should be different for no particular reason other than to account for a single phenomenon-viz. Poznań-Cracow Voicing.

A reviewer asks why it should be incorrect to assume systematically different underlying representations, and how exactly the grammar should handle the extraneous element $\{\mathrm{L}\}$. These issues are related. As for the underlying representations, it appears correct to assume that they are underspecified, taking advantage of privative elements. Since voice is not contrastive on sonorants and vowels, it should not be specified on such autosegments in the lexicon. This assumption has the following consequences for the handling of the extraneous $\{\mathrm{L}\}$. If the element is not found on non-obstruents in lexical representations, it is the task of phonology to add an $\{L\}$ to the left edge of each

\footnotetext{
${ }^{19}$ This is a consequence of what is known in GP as the Non-Arbitrariness Principle: "Processes apply whenever the conditions that trigger them are satisfied" (Kaye 1995: 291). An analysis of the application and the effects of external blocking of phonological processes - against Non-Arbitrariness Principle - is currently under development (Michalski, in prep.).
} 
word that does not begin with an obstruent. Crucially, the notion "word" should be reflected in phonology. Notice that in morphological terms the left edge of a (phonological) word in Polish may coincide with the left edge of a phonological exponent of a root, that of a prefix, or that of a preposition. Only the leftmost of these may trigger Poznań-Cracow Voicing. (Roots do not trigger Poznań-Cracow Voicing on prefixes, and neither of these categories triggers this type of voicing on prepositions.) It appears the use of the extraneous $\{L\}$ would require a system in which the $\{L\}$ would only be added to the left edge of a word once the whole word has been computed, but before it is concatenated with adjacent words. ${ }^{20}$

Thus, it must be concluded that an account of Poznań-Cracow Voicing - within the limitations on voice specification imposed by GP - has not been found, and appears impossible.

\section{Conclusion}

The article has briefly summarised the data about voice-related phenomena in Polish in general, and it has pointed to the systematic difference between Warsaw Polish and Poznań-Cracow Polish in particular. It is concluded that the phenomenon of PoznańCracow Voicing cannot be merely phonetic, because - as the data show - its occurrence can be very accurately defined in phonological and morphosyntactic terms. The brief summary of the analyses by Gussmann (1992) and Rubach (1996) has pointed out the triggering factor for Poznań-Cracow Voicing - viz. word-initial non-obstruents. Gussmann's (2007) analysis of regressive obstruent voice assimilation has been found not to cover Poznań-Cracow Voicing. It has been shown that the principles of voice specification in GP do not allow for a straightforward analysis of Poznań-Cracow Voicing as an instance of feature spread, which would be compatible with Gussmann's (2007) analysis and in accordance with Gussmann's (1992) and Rubach's (1996) earlier findings. An alternative in the form of the element $\{\mathrm{L}\}$ under the first "O" slot in words beginning with non-obstruents has been introduced. Its weaknesses have been assessed, and it has been concluded that the use of the element $\{L\}$ on non-obstruents, at least in the form presented, is not a viable solution for GP. Therefore, it is concluded that further research on Poznan-Cracow Voicing - if taken from the perspective of GP - should rather concentrate on the interpretative side of GP representations, taking into account that despite the phenomenon being phonological - not merely phonetic - it targets obstruents which - due to positional effects - are not contrastive in voice. An interpretative approach to Poznań-Cracow Voicing - among other phenomena - is currently under development (Michalski, in prep.).

\footnotetext{
${ }^{20}$ Needless to say, this would resemble the post-cyclic stage in LP.
} 


\section{REFERENCES}

Bethin, C.Y. 1992. Polish syllables. The role of prosody in phonology and morphology. Columbus, OH: Slavica Publishers.

Chomsky, N. and M. Halle. 1968. The sound pattern of English. (=SPE.) London - New York: Harper \& Row.

Cyran, E. 2003. Complexity scales and licensing strength in phonology. Lublin: Wydawnictwo KUL.

Gussmann, E. 1980. Studies in abstract phonology. Cambridge, MA: MIT Press.

Gussmann, E. 1992. "Resyllabification and delinking: The case of Polish voicing". Linguistic Inquiry 23(1): 29-56.

Gussmann, E. 2007. The phonology of Polish. Oxford: Oxford University Press.

Harris, J. 1994. English sound structure. Oxford: Blackwell.

Kaye, J. 1990. "“Coda' licensing”. Phonology 7. 301-330.

Kaye, J. 1995. "Derivations and interfaces". In: Durand, J. and F. Katamba (eds.), Frontiers of phonology. London - New York: Longman. 289-332.

Kaye, J., J. Lowenstamm and J.-R. Vergnaud. 1985. "The internal structure of phonological representations: A theory of Charm and Government". Phonology Yearbook 2. 305-328.

Kaye, J., J. Lowenstamm and J.-R. Vergnaud. 1990. "Constituent structure and government in phonology". Phonology 7. 193-231.

Michalski, G. (in preparation). Phonology with interfaces. The morphophonology and postlexical phonology of English and Polish. [PhD dissertation, Adam Mickiewicz University, Poznań.]

Mohanan, K.P. 1982. Lexical Phonology. [Unpublished PhD dissertation, Massachusetts Institute of Technology.]

Rubach, J. 1984. Cyclic and lexical phonology. The structure of Polish. Dordrecht: Foris.

Rubach, J. 1996. "Nonsyllabic analysis of voice assimilation in Polish. Linguistic Inquiry 27(1). 69-110.

Rubach, J. and G.E. Booij. 1990. "Edge of constituent effects in Polish”. Natural Language and Linguistic Theory 8. 427-463.

Scheer, T. 2004. A lateral theory of phonology. What is CVCV and why should it be? Berlin: Mouton de Gruyter. 